Universidad de Lima

Facultad de Derecho

Carrera de Derecho

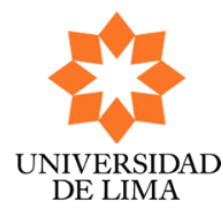

\title{
ARBITRAJE: "DERECHO ARBITRAJE MUNICIPAL" Y ADMINISTRATIVO: "PROTECCIÓN AL CONSUMIDOR"
}

Trabajo de Suficiencia Profesional para optar el Título

Profesional de Abogado

\section{TIYI MATA HIDALGO}

Código 20081551

Lima - Perú

Noviembre del 2019 


\title{
ARBITRAJE: "DERECHO ARBITRAJE MUNICIPAL" \\ Materia: Arbitraje \\ $\mathrm{N}^{\circ}$ de Expediente: 2269-2012-CCL \\ Demandante: I. E. T. \\ Demandado: Municipalidad Distrital de Jesús María
}

\begin{abstract}
Resumen
Proceso arbitral entre una entidad pública y una empresa privada, con la participación de la Cámara de Comercio de Lima. Se discute la validez de dos adendas firmadas a razón del contrato de arrendamiento de un bien inmueble de uso público y la aplicación de la ley correspondiente. El árbitro le da la razón a la entidad pública manifestando las adendas carecen de valor y que no corresponde la aplicación de la Ley de contrataciones con el Estado.
\end{abstract}

\section{ADMINISTRATIVO: "PROTECCIÓN AL CONSUMIDOR" Materia: Protección al consumidor-Discriminación $\mathrm{N}^{\circ}$ de Expediente: 001-2015-SIA/PSO-LAL \\ Demandante: Indecopi (de oficio) \\ Demandado: D. P. S. A. C.}

Sumilla:

Proceso iniciado de oficio a raíz de comentarios realizados en una red social acusando a una discoteca de discriminación por orientación sexual. La primera instancia se pronunció considerando que sí hubo discriminación; sin embargo, la segunda instancia revoca esta decisión argumentando que el trato diferenciado fue justificado. 